\title{
Comparison between Signum transform and Euler deconvolution in magnetic data of the Paranaguá Terrane, southern Brazil
}

Jessica D. Weihermann ${ }^{1}$, Francisco J. F. Ferreira ${ }^{2}$, Saulo P. Oliveira ${ }^{3}$, Leonardo F. Cury ${ }^{2}$. ${ }^{1}$ Programa de Pós-Graduação em Geologia da Universidade Federal do Paraná, 'Departamento de Geologia da Universidade Federal do Paraná, ${ }^{3}$ Departamento de Matemática da Universidade Federal do Paraná.

\section{Copyright 2016, SBGf - Sociedade Brasileira de Geofísica}

Este texto foi preparado para a apresentação no VII Simpósio Brasileiro de Geofísica, Ouro Preto, 25 a 27 de outubro de 2016. Seu conteúdo foi revisado pelo Comitê Técnico do VII SimBGf, mas não necessariamente representa a opinião da SBGf ou de seus associados. É proibida a reprodução total ou parcial deste material para propósitos comerciais sem prévia autorização da SBGt.

\begin{abstract}
Magnetic maps reflect the spatial distribution of magnetic sources, which may be located at different depths and have significantly different physical and geometrical properties, complicating the identification of the corresponding geologic structures. Most geophysical techniques are frenquently used to enhance geological structures. The Euler deconvolution is a semi-automatic interpretation method that is frequently used in the magnetic interpretation. The Signum transform is a simple derivative-based method for qualitative and quantitative interpretation of magnetic anomalies from discrete sources. In this paper we compare the application of Euler deconvolution and Signum transform for the estimation of the depth and width of magnetic sources of the Paranaguá Terrane.
\end{abstract}

\section{Introduction}

Magnetic data are crucial to geophysical approaches to geologic mapping, especially for structural information. These data have signals with large amplitude variation that originate from sources with different geometries, located at different depths and with different magnetization properties.

Enhancement methods can be used to emphasize certain characteristics in the data resulting to facilitate qualitative geological interpretation of the anomalies. Most methods used for enhancing magnetic data are based on vertical or horizontal derivatives of magnetic anomalies or combinations of them.

This work concerns the utility of enhancement methods for the estimation of the depth and width of magnetic sources of the Paranaguá Terrane. The Paranaguá Terrane, located in the coastal portion of the states of Santa Catarina, Paraná and São Paulo (Fig. 1), Southern Brazil, is marked to the east by the Brazil shoreline, the southwest by gneissic-granulite rocks of the Luis Alves Microplate and the northwest by Curitiba Microplate (Fig. 2). All the occidental contact is tectonic, being represented in its south-southwest portion by the Palmital lineament and in the west-northwest by Alexandra and Serra Negra lineaments. It is characterized by an igneous complex, with a variety of granitic rocks distributed from the northeast of the Santa Catarina State to the southeast of the São Paulo State, represented by Morro Inglês, Rio do Poço and Canavieiras-Estrela Suites and the gneiss and gneissic-migmatitic country rocks inserted into São Francisco Complex and the metasedimentary rocks in the Rio das Cobras Sequence (Cury, 2009). In the magnetic maps of the Paranaguá Terrane there is the influence of the swarm of dykes of the Ponta Grossa Arch, with a NWSE trend and an extension superior to $600 \mathrm{~km}$ and width ranging from 20 to $100 \mathrm{~km}$ (Portela Filho \& Ferreira, 2003).

Euler deconvolution is a semi-automatic interpretation method that is frequently used with magnetic and gravity data. For a given source type, which is specified by its structural index (SI), it provides an estimate of the source location. The Signum transform was automatized by an algorithm developed by Oliveira et al. (2015) and, for a vertical magnetization the edges of the sources can be recognized from the locations where one or more of the spatial derivatives change its sign. The present work is part of the research developed in the master's thesis of Weihermann (2016) and the main focus of this paper is compare the results of Euler deconvolution and Signum transform in the magnetic data of Paranaguá Terrane.

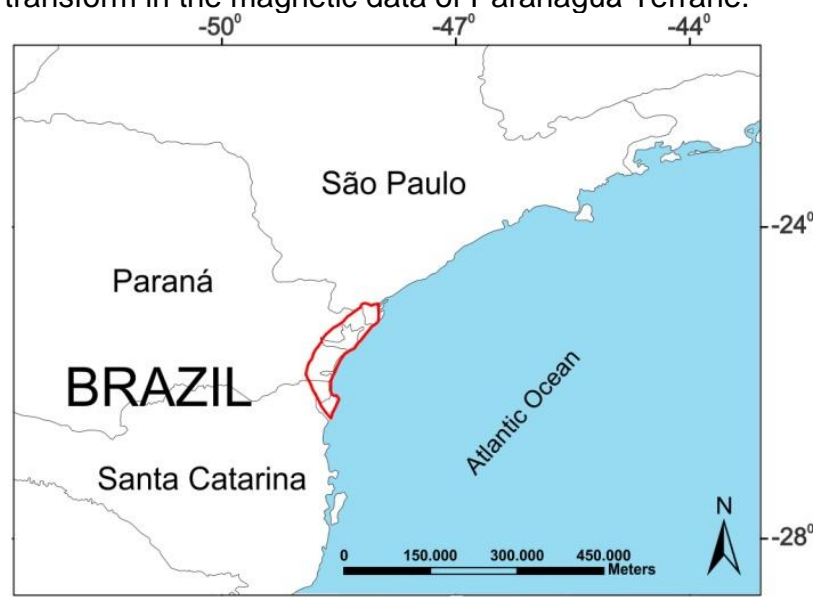

Figure 1 - Location of the Paranaguá Terrane indicated in red.

\section{Methodology}

In the present research, we have processed and interpreted magnetic data of the Paranaguá Terrane (Fig. 2) from the Aerogeophysical Paraná-Santa Catarina Project (CPRM 2011). First we have applied the Signum transform in a theoretical model (Fig.3) to evaluate his effectiveness. Then we applied the algorithm proposed by Oliveira et al. (2015) for estimate the automatic depth and width of the magnetic sources based on Signum 
transform method (de Souza \& Ferreira, 2012, 2013, 2015).

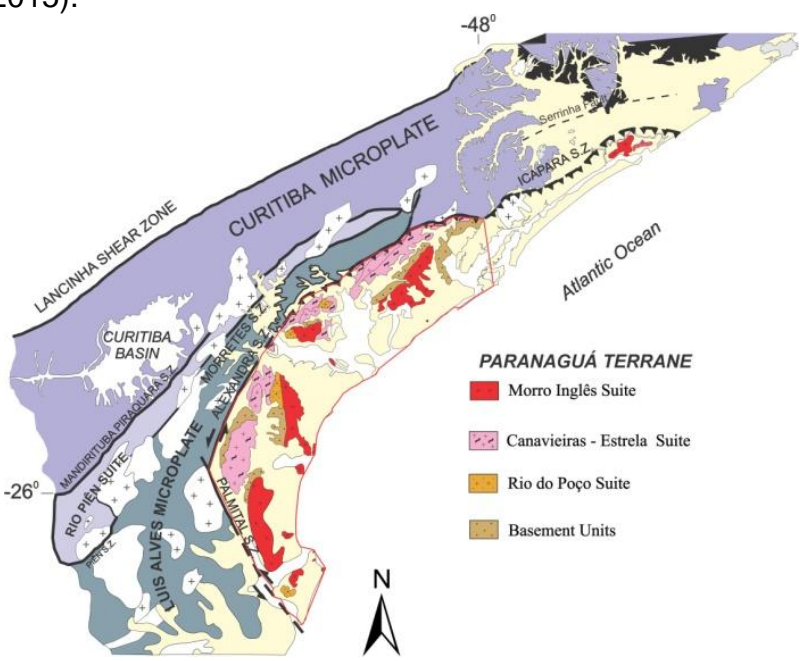

Figure 2 - Geological map of the Paranaguá Terrane indicated in red.

The magnetic anomaly was firstly enhanced using an edge detection filter based on the Signum transform, represented in equation (1) which retains only the signs of the anomalous field (Oliveira et al. 2015):

$\operatorname{ST}[f](x)=\left\{\begin{array}{l}\frac{f(x)}{|f(x)|}, f(x) \neq 0 \\ 1, f(x)=0\end{array}\right.$

where $f$ could be:

$f=M z=\frac{d M}{d z}, f=\frac{d^{2} M}{d^{2} z} \quad$ and $\quad f=\frac{d M}{d z}-\left|\frac{d M}{d x}\right|$ and $M$ is the magnetic anomaly. The values of $S T[f]$ are expected to be 1 over the sources and -1 out of them.

The equations of depth (h) and width (a) of the sources are described by equation 2 :

$h=\left(x_{v h+}-x_{v h-}\right) / 2, a=\sqrt{x_{v}^{2}-h^{2}}$

where $x_{v h \pm}=h \pm \sqrt{a^{2}+2 h^{2}}$ and $x_{v}=\sqrt{a^{2}+h^{2}}$

The Euler deconvolution provides a quick estimation of the location and geometry of the anomalous sources from potential data without the need to presume the direction of the magnetization vector. This method is based on equation 3 (Reid et al. 1990):

$(x-x o) \frac{d T}{d x}+(y-y o) \frac{d T}{d y}+(z-z o) \frac{d T}{d z}=-\eta T$

Where $\left(x_{0}, y_{0}, z_{0}\right)$ is the position of the magnetic source where the magnetic field $(T)$ is detected from $x, y, z, \eta$ is the structural index being a measure of the rate of decay of magnetic anomaly with a distance between the source and the measurement point, i.e., an indicative of the geometric shape of the anomalous source (eg. $\eta=0$ for a contact, $\eta=1$ for a vertical dyke or sill, $\eta=2$ for a cylinder horizontal or vertical and $n=3$ for a sphere or a dipole).

We applied the enhancement methods in a model composed by two prisms, P1 (length $=1600 \mathrm{~m}$, width =
$400 \mathrm{~m}$, thickness $=2000 \mathrm{~m}$ ) and $\mathrm{P} 2$ (length $=1600 \mathrm{~m}$, width $=600 \mathrm{~m}$, thickness $=2000 \mathrm{~m}$ ) with their tops located at depth $z 1=100 \mathrm{~m}(\mathrm{P} 1)$ and $\mathrm{z} 2=300 \mathrm{~m}$ (P2), as indicated in the Figure 3 . The bodies are located in the north geomagnetic pole $(86.270 \mathrm{~N}, 159.180 \mathrm{~W})$, with inducing field intensity $B=57091 \mathrm{nT}$, direction $(D, I)=\left(0^{0}\right.$, $90^{\circ}$ ), and magnetic susceptibility $\mathrm{k}=0.0276 \mathrm{SI}$, resulting in an induced magnetization $\mathrm{Ji}=0.5 \mathrm{~A} / \mathrm{m}$. Then these techniques were applied to real data of the Paranaguá Terrane.

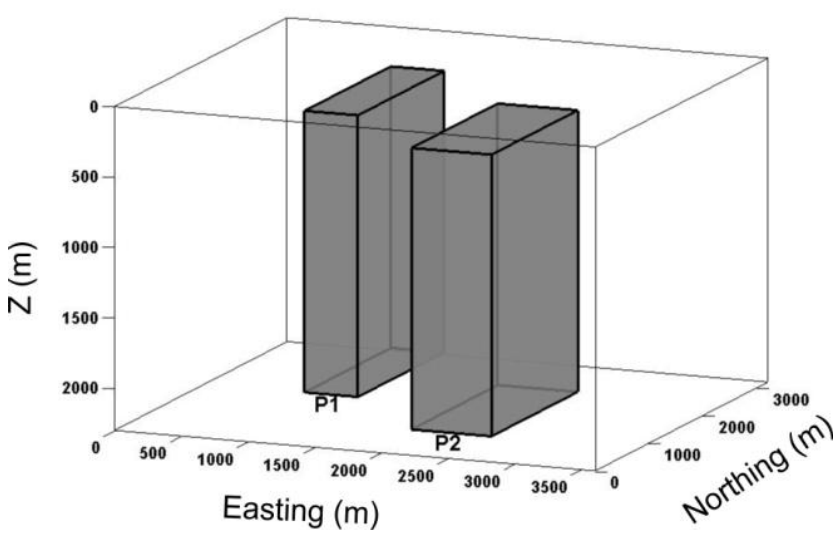

Figure $3-3 D$ magnetic model used to evaluate the Signum transform.

\section{Results and Discussion}

The Figure $4(a, b)$ presents the depth (a) and width (b), given by the application of the algorithm (Oliveira et al. 2015) based on the Signum transform method. The algorithm (Oliveira et al. 2015) is an automatization of the enhancement technique Signum transform, which allows the calculation of estimated depth and width of the magnetic sources. The results from depth correspond to approximately $75 \%$ from the original prism depth, and the results from width correspond to approximately $84 \%$ from the original prism width (Fig. 3).

These methods were applied to the magnetic data of the Paranaguá Terrane. The magnetic data were corrected from diurnal variation, parallax error, leveling of profiles and removal of IGRF calculated at flight height referred to year 2010. The Paranaguá Terrane has an inducing field intensity of $B=22822 n T$, direction $(D, I)=\left(-18.9^{0}\right.$, $35.8^{\circ}$ ) at the coordinates $25^{\circ} 30^{\prime} \mathrm{S}$ and $48^{0} 30^{\prime} \mathrm{W}$ in 2010 04-22, and magnetic susceptibility $\mathrm{k}=0.0276 \mathrm{SI}$, resulting in a induced magnetization $\mathrm{Ji}=0.5 \mathrm{~A} / \mathrm{m}$. The $\mathrm{TMl}$ data (Fig.5) was reduced to the pole (RTP) using a magnetic inclination of $-35.8^{0}$ and a declination of $-18.9^{0}$, which corresponds to the magnetic field at the time of the airborne survey in the center of the study area. After the reduction to the pole we applied the upward continuation method to an elevation of $500 \mathrm{~m}$, to reduce the noise and aid delineation of deeper structures (Fig. 6). 
a)

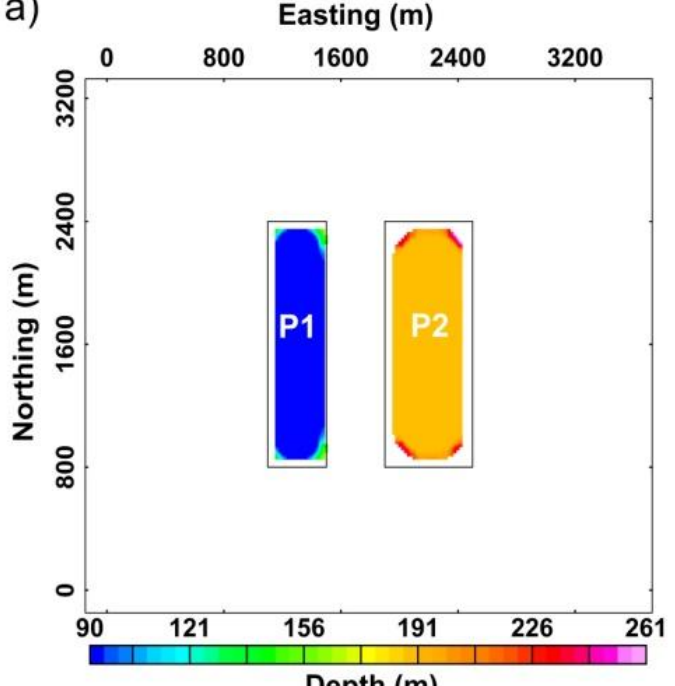

b)

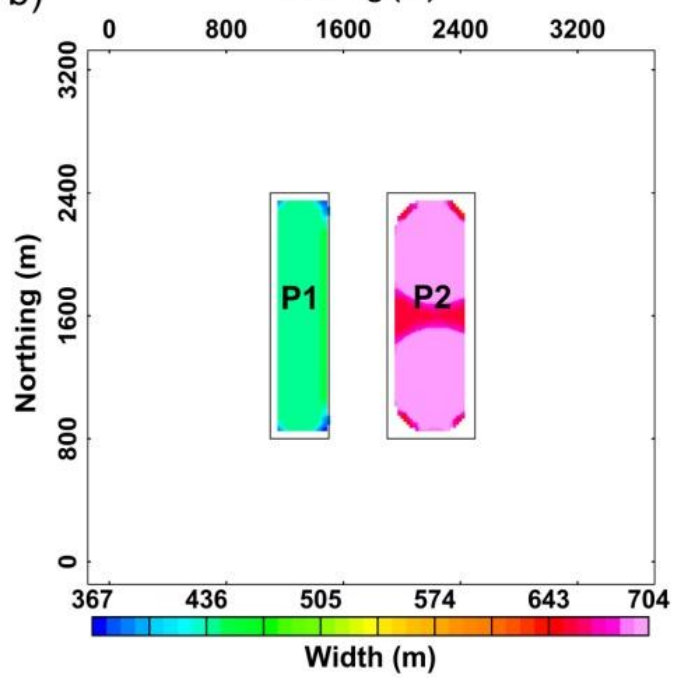

Figure 4 - (a) Depth and (b) width of the prisms in Figure 3 estimated from Signum transform.

The upward continuation (UW) calculates the potential field that would have been recorded at a higher level above the acquisition level. The UW method provides a robust method of frequency separation in potential field data (Jacobsen 1987) that is locally adaptive and produces a visualization of the data that is more geologically interpretable than using a fixed frequency or band-pass filter. After this process we applied the signum transform in the real data.

As the study area reflects the influence of the dykes in a NW-SE trend, we applied a directional cosine filter along the direction of magnetic declination $\left(-18.9^{\circ}\right)$ in the magnetic data of the Paranaguá Terrane, using a $2^{0}$ of cosine function, to reduce the high frequency signs and to enhance structures in a different direction. Figure 7 and 8 shows the TMI data and the TMI reduced to the pole upward continued $500 \mathrm{~m}$ with the directional cosine filter applied, respectively.
The algorithm proposed by Oliveira et al. (2015) was applied to the Paranaguá Terrane data, with the purpose of estimate the depth and width of dyke-like magnetic sources. The edges of the magnetic sources can be recognized from the locations where one or more of the spatial derivatives change its sign, the zero crossover points, identified by the Signum transform (de Souza \& Ferreira, 2012, 2013, 2015). The sources depths and widths were calculated using the distances between the center of the filtered anomalies and the zero crossover points, as input values (Oliveira et al. 2015). These data were compared with the Euler deconvolution (Thompson 1982).

Euler deconvolution is a semiquantitative method that is frequently used in the magnetic interpretation. For a given source type, which is specified by its structural index (SI), it provides an estimate of the source location. In this case, it was used a contact model solution $(\mathrm{SI}=0)$, with a tolerance of $5 \%$ and with a window size equal to $10 \mathrm{~m}$ (Fig. 9a).

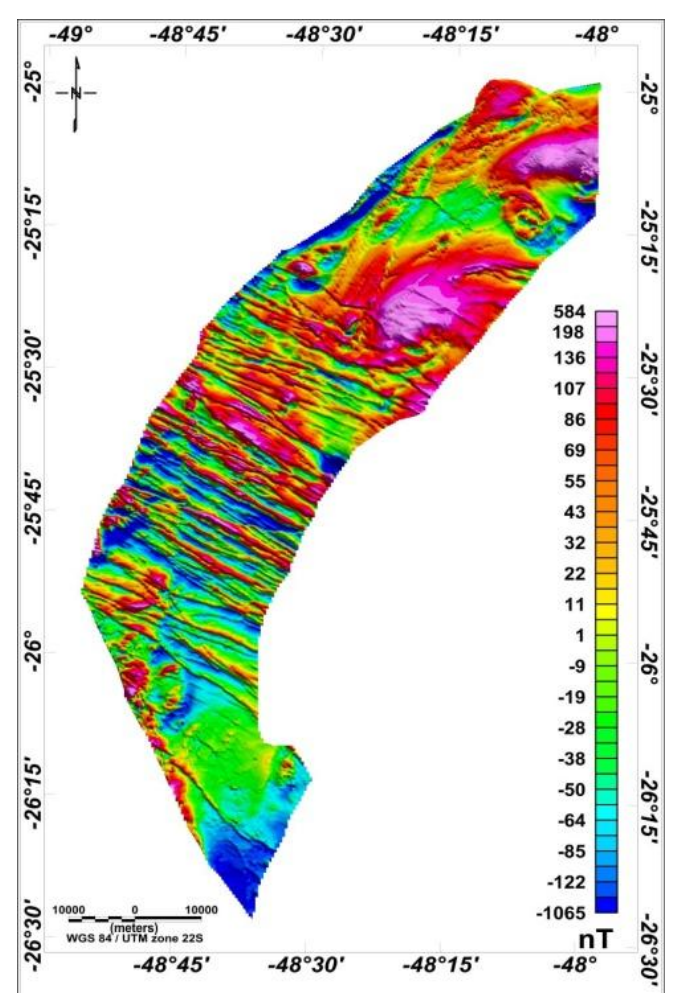

Figure 5-TMI data of the Paranaguá Terrane. 


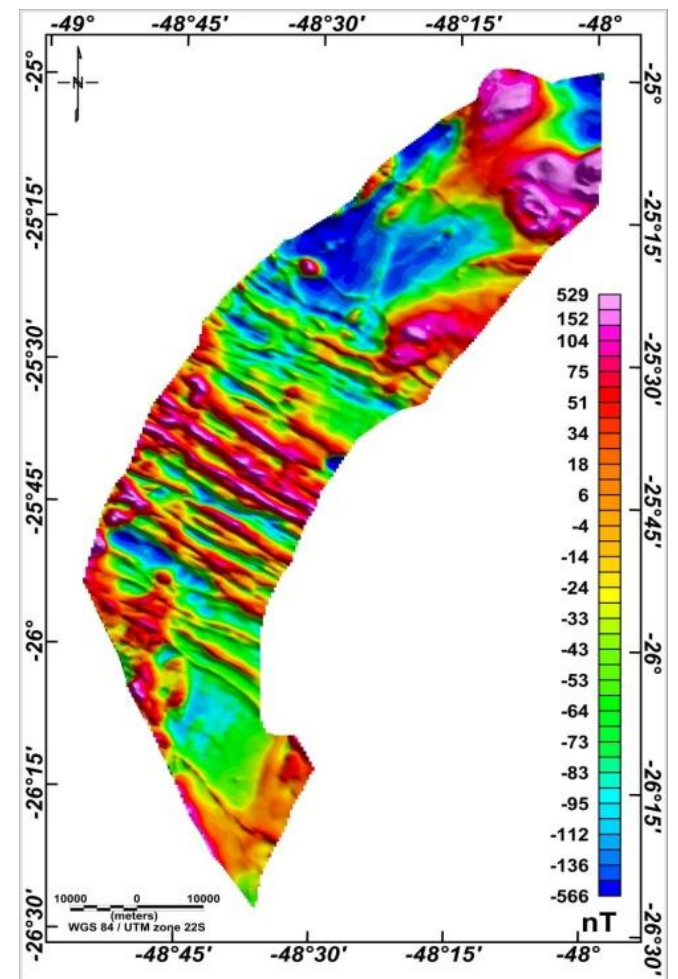

Figure 6 - TMI data of the Paranaguá Terrane reduced to the pole upward continued $500 \mathrm{~m}$.

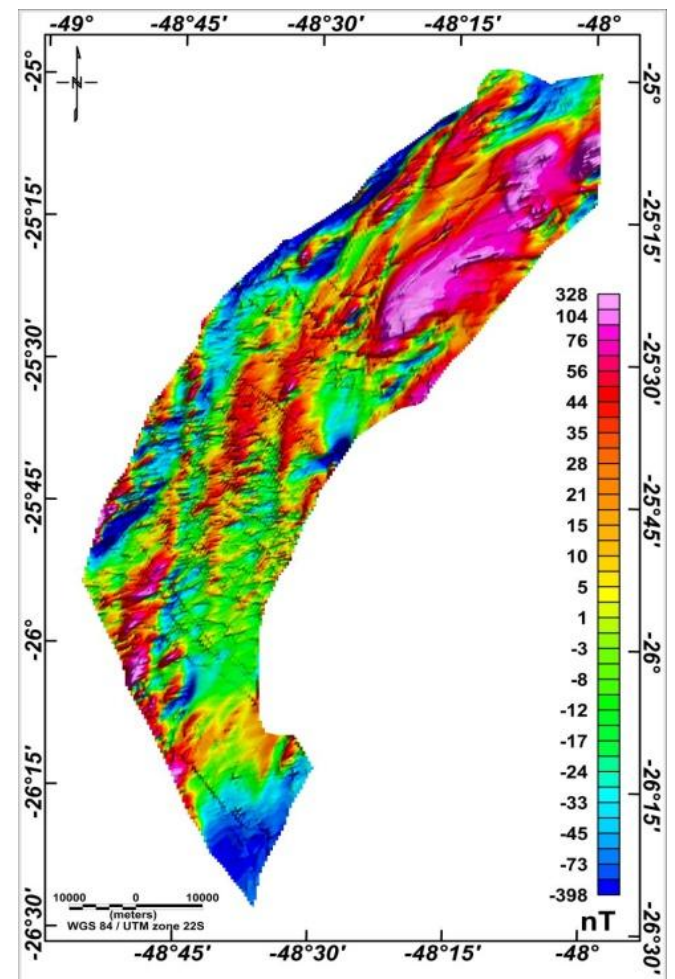

Figure 7 - Directional cosine filter applied to TMI data of the Paranaguá Terrane.

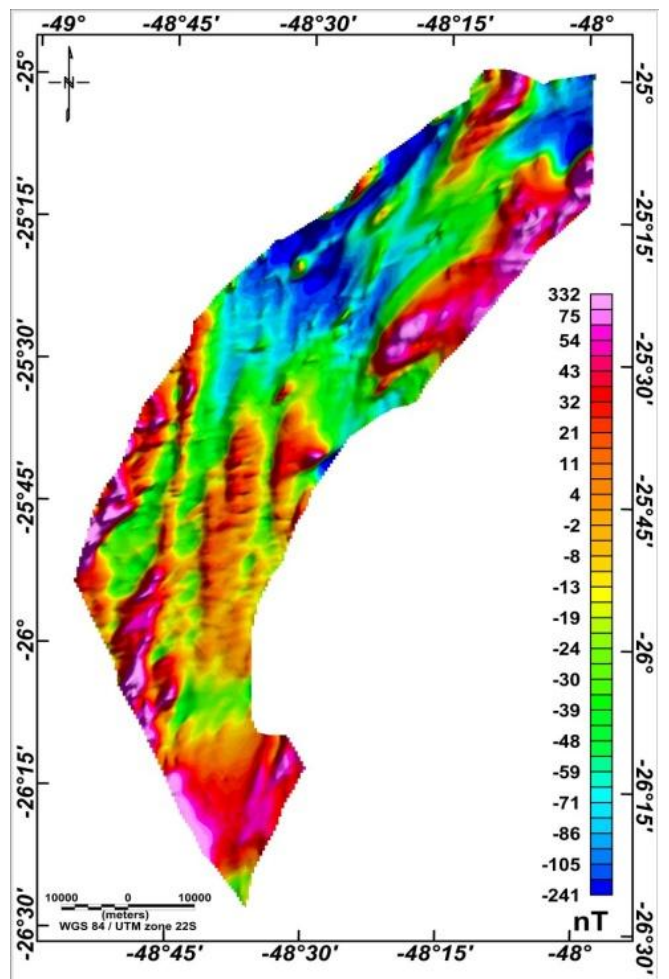

Figure 8 - Directional cosine filter applied to TMI data of the Paranaguá Terrane reduced to the pole upward continued $500 \mathrm{~m}$.

Figure 9 shows the comparison of the signum transform with the Euler deconvolution. It is possible to note that they qualitatively agree with each other. This algorithm allows an improvement of Euler, as can be seen in Figure $9 \mathrm{~b}$. The depths vary from shallow bodies with less than $200 \mathrm{~m}$ and deeper bodies with more than $600 \mathrm{~m}$, and with intermediate responses varying from $200-400 \mathrm{~m}$ and 400 $600 \mathrm{~m}$. The same algorithm was applied to the directional cosine data, and the results are shown in Figure 10. It is possible to note that the depths estimated with the Euler deconvolution also qualitative agree with the algorithm. The Figure 10b presents the results from the application of the Oliveira et al. (2015)' algorithm, and also is possible to note that the responses presented are better to analyze than Euler's. The bodies depth lies on the range of shallow, less than $200 \mathrm{~m}$ and in between 200-400 m, and with a lower presence of deeper bodies (400-600 $\mathrm{m}$ and higher than $600 \mathrm{~m}$ ). Figure 11 shows the application of the Oliveira et al. (2015)' algorithm in the Paranaguá Terrane magnetic data to determine the bodies width. In Figure $11 \mathrm{~b}$ this algorithm was applied in the directional cosine data. The magnetic sources of the Paranaguá Terrane have an estimated width mainly between $600 \mathrm{~m}$ and $1400 \mathrm{~m}$ and more than $1400 \mathrm{~m}$. Such estimates are overstated as a result of the upward continuation $(500 \mathrm{~m})$ of the magnetic data and due to the flight line spacing $(500 \mathrm{~m})$. It is possible to note that in Figure 11a there are more shallow bodies than Figure 11b. 
a)

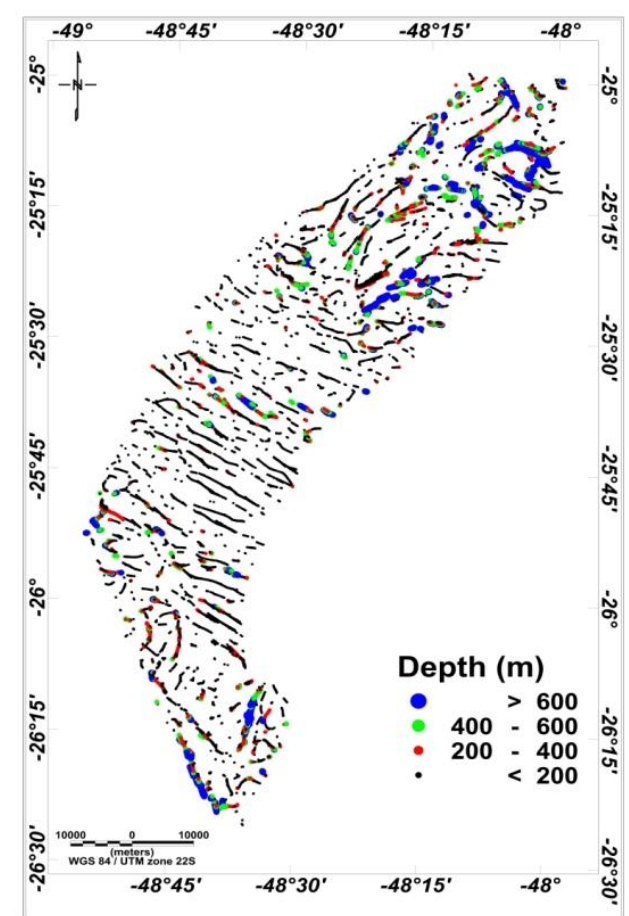

b)

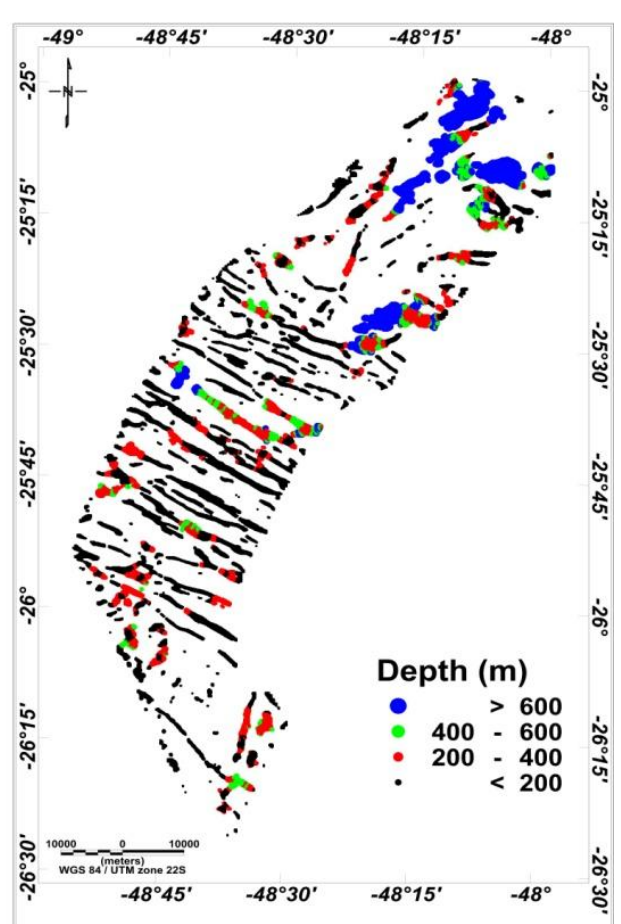

Figure 9 - (a) Estimated depth from Euler deconvolution and (b) from the Oliveira et al. (2015)' algorithm of the Paranaguá Terrane.

a)

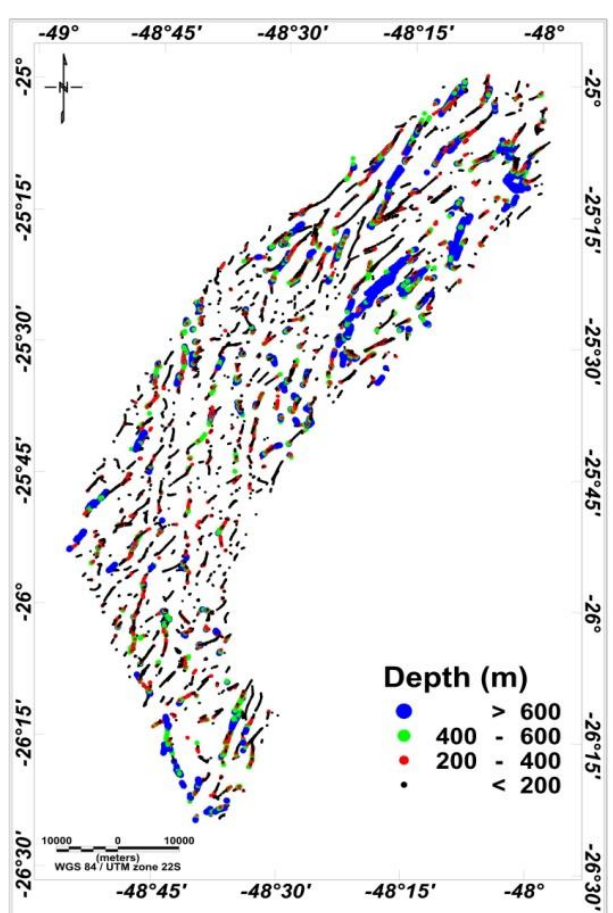

b)

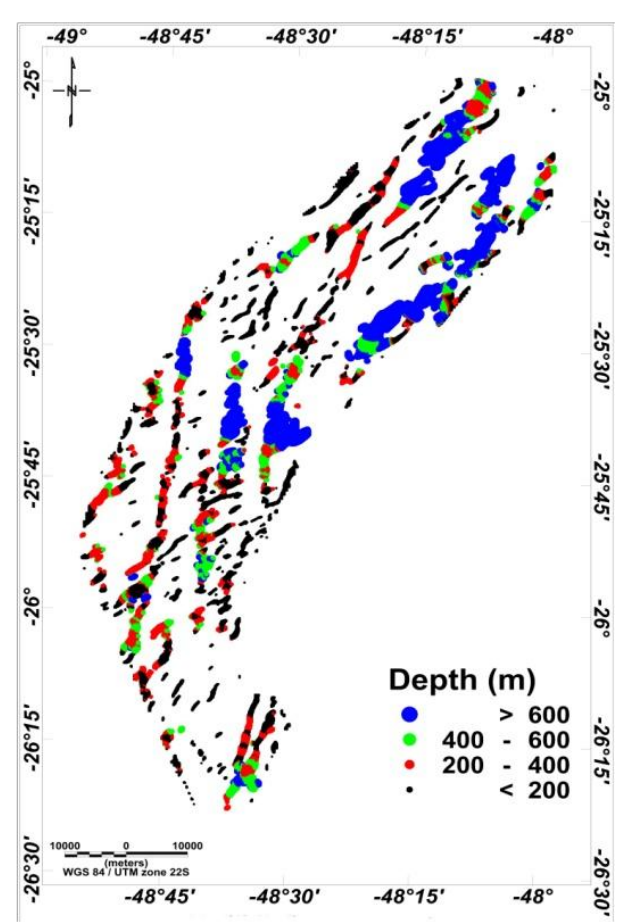

Figure 10 - Directional cosine filter applied to (a) estimated depth from Euler deconvolution and (b) from the Oliveira et al. (2015)' algorithm of the Paranaguá Terrane. 
a)

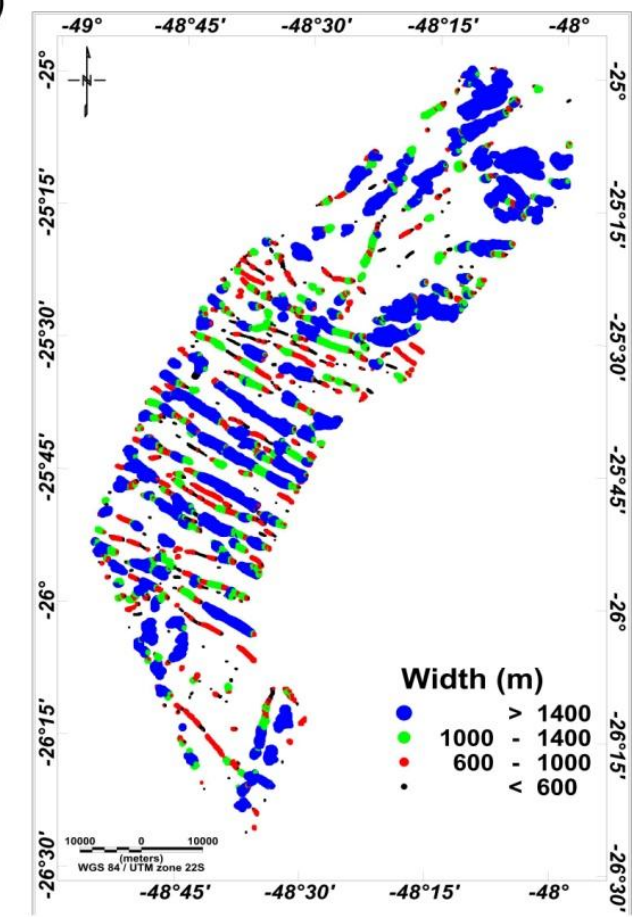

b)

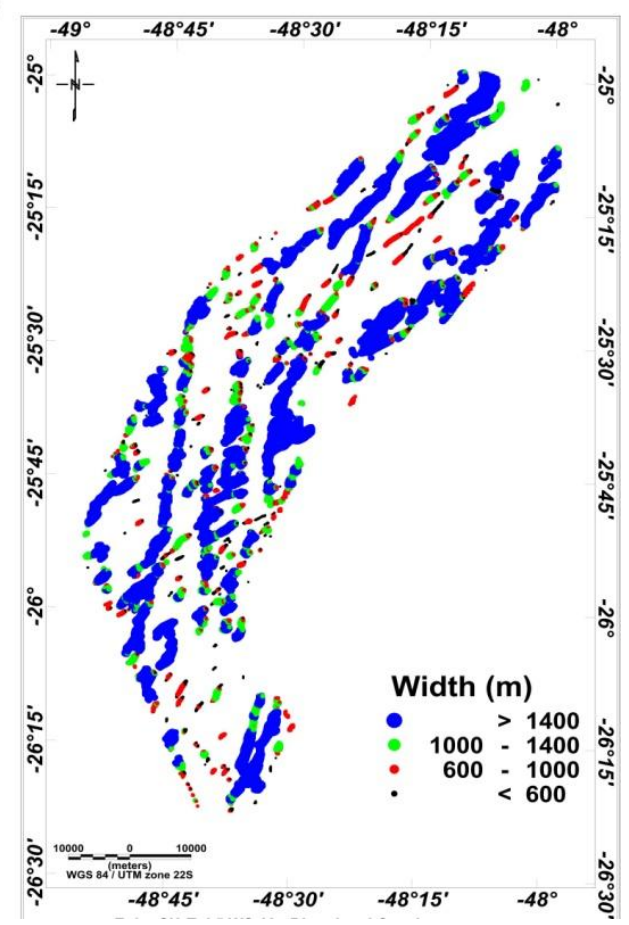

Figure 11 - Application of the Oliveira et al. (2015)' algorithm to estimate the width of the magnetic bodies, in the (a) magnetic data and in the (b) directional cosine data.

\section{Conclusions}

The applicability of an algorithm based on Signum transform in the magnetic data of the Paranaguá Terrane proved to be a good semi-quantitative method in comparison with Euler Deconvolution. The responses of this method showed great consistency with the real data, revealing less number of solutions and facilitating the interpretation. For this reason the Signum transform algorithm could be considerate as an alternative to the traditional Euler deconvolution method.

\section{Acknowledgments}

We are grateful to the Companhia de Pesquisa de Recursos Minerais (CPRM, Geological Survey of Brazil) who allowed the use and publication of airborne geophysical data in the region of Paranaguá Terrane. To the Universidade Federal do Paraná for the institutional support. J.D. Weihermann is grateful to Coordination for the Improvement of Higher Education Personnel (CAPES) for the scholarship. F.J.F. Ferreira was supported in this research by a fellowship from National Council for Scientific and Technological Development (CNPq) (contract 306978/2015-6).

\section{References}

CPRM 2011. Programa Geologia do Brasil (PGB) Projeto Aerogeofísico Paraná- Santa Catarina Relatório final do levantamnto processamento dos dados maanetométricos e aamaespectrométricos.
Cury L. F. 2009. Geologia do Terreno Paranaguá. Tese de Doutorado, Instituto de Geociências, Universidade de São Paulo, São Paulo, 202p. In Portuguese

Jacobsen, B.H. 1987. A case for upward continuation as a standard separation filter for potential-field maps. Geophysics 52(8):1138-48.

Portela Filho, C. V. \& Ferreira, F.J.F. 2003. Processamento e interpretação de dados aeromagnéticos da região central do Arco de Ponta Grossa (Bacia do Paraná). In: 8th International Congress of the Brazilian GeophysicalSociety. In Portuguese.

Reid, A. B., Allsop, J. M., Granser, H., Millett, A. J., and Somerton, I. W., 1990, Magnetic interpretation in three dimensions using Euler deconvolution: Geophysics, 55: 80-91.

de Souza, J., Ferreira, F.J.F. 2012. On the use of derivatives for interpreting magnetic anomalies due to dyke-like bodies: qualitative and quantitative analysis. In: Istanbul 2012 International Geophysical Conference and Oil \& Gas Exhibition, 2012, Istanbul. Istanbul 2012 International Geophysical Conference and Oil \& Gas Exhibition. v. 1. p. 1-4.

de Souza, J., Ferreira, F.J.F. 2013. On the use of derivatives for interpreting magnetic anomalies due to dyke-like bodies II: application to synthetic and field data. SEG Houston 2013 Annual Meeting. 
de Souza, J., Ferreira, F.J.F. 2015. The application of the Signum transform to the interpretation of magnetic anomalies due to prismatic bodies. In: 24th International Geophysical Conference and Exhibition, 2015, Perth, Western Australia. ASEG Extended Abstracts 01/2015; 2015(1). DOI: 10.1071/ASEG2015ab190.

Thompson, D. T. 1982. EULDPH: A new technique for making computer- assisted depth estimates from magnetic data: Geophysics, 47:31-37.

Weihermann, J.D. 2016. Integração geofísico-geológica do Terreno Paranaguá, Sul do Brasil. Dissertação de Mestrado, Departamento de Geologia, Universidade Federal do Paraná, Curitiba, 101p. In Portuguese 